\title{
Spinocerebellar ataxia type 13
}

INSERM

\section{Source}

INSERM. (1999). Orphanet: an online rare disease and orphan drug data base.

Spinocerebellar ataxia type 13. ORPHA:98768

Spinocerebellar ataxia type 13 (SCA13) is a very rare subtype of type I autosomal dominant cerebellar ataxia (ADCA type l; see this term). It is characterized by onset in childhood marked by delayed motor and cog nitive development followed by mild progression of cerebellar ataxia. 